\section{Ascorbic Acid and the Common Cold: Evaluation of its Efficacy and Toxicity}

\section{PART I}

\author{
By LINUS PAULING, Ph.D.
}

Dr. Pauling is President of the Linus Pauling Institute of Science and Medicine, 2700 Sand Hill Road, Menlo Park, Calif. 94025, and Professor Emeritus of Chemistry at Stanford University and the California Institute of Technology.

Brief descriptions are given of the thirteen controlled trials that have been made of ascorbic acid in comparison with a placebo in relation to the common cold, with the ascorbic acid or placebo given to subjects over a period of time and with the subjects in good health at the beginning of the trial and exposed to cold viruses in the ordinary way. The integrated morbidity (amount of illness per person) found in these trials was an average of $36 \%$ less for the ascorbic-acid subjects (average intake $1 \mathrm{~g}$ per day) than for the placebo subjects. Several investigators have reported that no serious adverse effects of ascorbic acid were observed. So far there is no significant evidence for the various adverse reactions that have been hypothesized. The apparent benefit in health from an increase in intake of ascorbic acid justifies its widespread use.

In a recent article ${ }^{1}$ Dykes and Meier discussed some of the clinical data published since 1938 on the efficacy of pharmacologic doses of ascorbic acid in the prevention and treatment of the common cold and both clinical data and data obtained from intact animals that relate to the possible toxicity of ascorbic acid. They pointed out that in several studies the subjects receiving ascorbic acid had less illness than those receiving the placebo, but they criticized most of the studies with respect to some details of design or execution and concluded that there is little convincing evidence of a protective effect large enough to be clinically important. They also stated that many hypothetical adverse reactions to the intake of large amounts of ascorbic acid have been suggested, but that there is little evidence about the possible incidence of such reactions currently available.

The conclusions reached by Dykes and Meier have been widely misrepresented in press releases, newspapers, and magazines. For example, it has been said, on the basis of their paper and another paper published at the same time ${ }^{2}$, that "Vitamin $\mathrm{C}$ will not prevent or cure the common cold". ${ }^{3}$ In fact, their conclusion was that "Until such time as pharmacologic doses of ascorbic acid have been shown to have obvious, important clinical value in the prevention and treatment of the common cold, and to be safe in a large varied population, we cannot advocate its unrestricted use for such purposes." Moreover, some significant studies in this field were not mentioned by Dykes and Meier, and some important aspects of the studies discussed by them were also not mentioned by them. My conclusions, presented below, from the thorough analysis of the existing information, are somewhat different from those of Dykes and Meier.

Dykes and Meier mention that the evaluation of efficacy may be made uncertain by its partial dependence on subjective reports by the patients. The number of colds is especially unreliable because of uncertainty as to whether or not to record as a cold a mild indisposition lasting only one or two days. I consider the average number of days of illness per person (the integrated morbidity ${ }^{4}$ ) to be the best quantity to use in determining the relative efficacy of ascorbic acid and placebo. This quantity, which can be assessed in a reasonably objective way (by signs recorded by the physician, number of days of absence from school or work, etc.), is emphasized in the following discussion.

\section{COWAN, DIEHL, AND BAKER}

In the study by Cowan, Diehl, and Baker $^{5} 208$ students in the University of Minnesota received about $200 \mathrm{mg}$ of vitamin $\mathrm{C}$ per day for 28 weeks and 155 students received a placebo. Dr. Cowan has written me that the study was a double-blind one. The average number of days lost from school per person was 1.1 for the ascorbic-acid group and 1.6 for the placebo group, with standard deviations not given. 1fhis measure of the integrated morbidity thus shows $31 \%$ (range 26 to $36 \%$ ) less illness per subject for the ascorbicacid subjects than for the placebo subjects. The information given in the paper does not permit an accurate calculation to be made of the statistical significance of the rejection of the null hypothesis that ascorbic acid and the placebo have the same effect. I have made the conservative estimate ${ }^{4}$ that $\mathrm{P}$ is less than 0.02 .

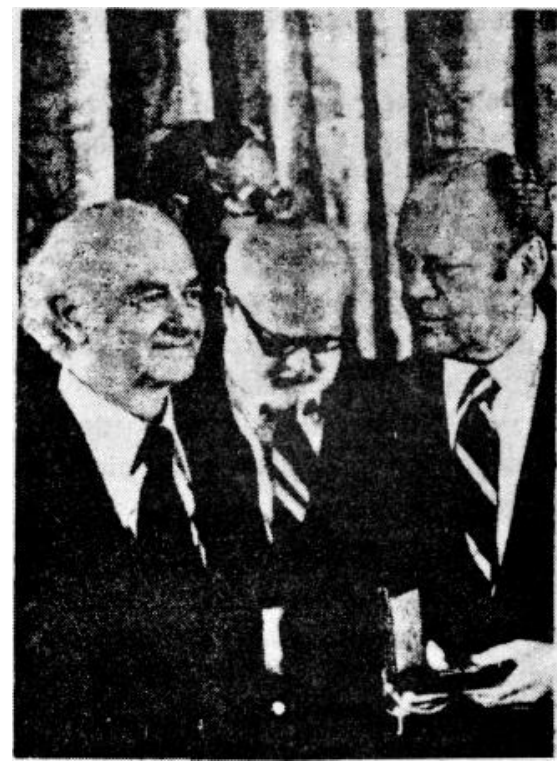

Dykes and Meier have criticized this study on several points. I may add that the investigators were at fault in not reporting their observations precisely (rounding off the average number of days of illness and not giving the standard deviations).

\section{FRANZ, SANDS, AND HEYL}

Franz, Sands, and Heyl carried out a double-blind study in Dartmouth Medical School with 89 volunteer med- 
ical students. ${ }^{6}$ They were divided in a random way into four groups, receiving ascorbic acid (205 mg per day), ascorbic acid and a bioflavonoid, a placebo, or the bioflavonoid alone. No effect of the bioflavonoid was observed. The number of colds in the combined ascorbic-acid groups was 14 (for 44 subjects) and that in the placebo groups was 15 (for 45 subjects). The number of colds not cured or improved in 5 days was only 1 for the ascorbic-acid group, much less than the value 8 for the placebo group. The authors state that "those receivin:: ascorbic acid showed more rapid improvement in their colds than those not receiving it .. . statistically significant at the 0.05 level." My estimate of the statistical significance (based on the assumption mentioned in the following paragraph) is $\mathrm{P}$ (one-tailed) $=0.01$. Dykes and Meier state that I apparently used an erroneous summary result; their treatment of the data gives $\mathrm{P}$ (one-tailed) $<0.0283$, P (two-tailed) $<0.0566$. We all agree that the null hypothestis of equal effect jaf ascorbic acid and placebo is to be rejected.

I have estimated the average number of days of illness per person for the two groups by making the assumption that the distribution function for colds in respect to their duration is the one given by observations made in another investigation. ${ }^{7}$ This calculation leads to the conclusion that the integrated morbidity per person was $40 \%$ less for the ascorbic-acid subjects than for the placebo subjects.

\section{RITZEL}

Ritzel $^{8}$ reported observations made in a double-blind study on 279 schoolboys, 15 to 17 years old, on two weeklong stays in a ski camp. Half of the subjects (139) received $1 \mathrm{~g}$ of ascorbic acid each day, and the other half (140) a placebo. There were 17 colds in the ascorbic-acid subjects •(total days of illness 31 ) and 31 -colds in the placebo subjects (total days of illness 80 ). The number of total individual signs and symptoms recorded by the physicians in their daily inspections of the subjects was 42 for the ascorbic-acid subjects and 119 for the placebo subjects. The integrated morbidity is $63 \%$ less for the ascorbic-acid group than for the placebo group (average of $61.0 \%$ from average days of illness per person and $64.5 \%$ from average number of recorded signs and symptoms). The statistical significance of this difference is high, $\mathrm{P}$ (one-tailed) $<0.01$.

Dykes and Meier criticize Ritzel on several points, and do not mention the results that he reported. One criticism is that he does not give in his tables the total number of colds in each group. They state that "Pauling infers the number of subjects by dividing 'illness days' by 'mean illness days' and concludes that there is a significant difference in proportions of subjects experiencing colds. If his interpretation is correct, the difference is indeed significant."

It is hard for me to understand why Dykes and Meier should suggest that my interpretation might be incorrect. It involves a very simple calculation. Ritzel states (in his Table 1) that the total number of days of illness for the ascorbic-acid subjects was 31 . He also states (page 66) that the average number of days per episode of illness was 1.8. The ratio $31 / 1.8$ is 17.2 ; that is, there were 17 episodes of illness in this group. A similar calculation gives 31 colds for the placebo subjects (80 total days of illness, 2.6 average number of days per episode). It is safe to assume that no subjects had two colds in the same week. With this assumption, the null hypothesis of equal probability of colds for the two groups is rejected at the level P (one-tailed) $<0.015$.

Dykes and Meier mention that I give great weight to the Ritzel study. I do give great weight to it, and I find it strange that they should reject it on the basis of trivial complaints, such as their apparent failure to understand the simple calculation described above.

\section{ANDERSON, REID, AND BEATON}

In the 1972 double-blind Toronto study $^{9,10} 407$ subjects received ascorbic acid ( $1 \mathrm{~g}$ per day plus $3 \mathrm{~g}$ per day for 3 days at the onset of any illness) and 411 subjects received a closely matching placebo. The duration of the study was four months. The number of days confined to house per subject was $30 \%$ less for the ascorbic-acid group than for the placebo group, and the number of days off work per subject was $33 \%$ less. The authors mention that these differences have high statistical significance $(\mathrm{P}<0.001)$.

Dykes and Meier present these results with little comment, except to state that the observed effect is considerably less than had been predicted by me. ${ }^{4}$ This is true; I predicted about twice as much protection, on the basis of the study by Ritzel. I surmise that two effects may be involved in this difference. First, the amount of protection, relative to the placebo subjects, is probably less when the basic intake of ascorbic acid is high (Toronto) than when it is low (Switzerland), and second, the observed protection is probably less in a long test (4 months) than in a short one (one week).

Anderson, Reid, and Beaton reported also a smaller amount (by $40 \%$ ) of non-respiratory illness in the ascorbic-acid subjects than in the placebo subjects.

\section{ANDERSON, SURANYI, AND BEATON}

A second double-blind study, with over 2000 subjects, was also carried out in Toronto. ${ }^{11}$ In this very large study there were two placebo groups, one with 285 and the other with 293 subjects, and six ascorbic-acid groups (receiving various amounts), with 275 to 331 subjects. The study continued for three months.

A complication in the analysis of this study is presented by the fact that the results observed for the two placebo groups do not agree with one another. One placebo group had the greatest amount of illness of all eight groups, and the other had the smallest amount. The authors conclude that their observations are compatible with an effect of small magnitude (less than 20\%) from both the prophylactic regimen (250 mg, $1 \mathrm{~g}$, or $2 \mathrm{~g}$ of ascorbic acid per day) and the therapeutic regimen (4 or $8 \mathrm{~g}$ on the first day of illness), with an effect of somewhat greater magnitude from the combined regimen $(1 \mathrm{~g}$ per day and $4 \mathrm{~g}$ on the first day of illness). They state also that there was no evidence of side effects from the $1 \mathrm{~g}$ or $2 \mathrm{~g}$ of ascorbic acid per day and no evidence of a rebound increase in illness during the month following withdrawal of the daily vitamin supplement. 
The authors give the amounts of illness per subject (days of symptoms, days indoors, days off work) relative to the first placebo and relative to tj)e first plus the second (there is sonpe reason to suspect that the second placebo group was not a representative sample of the general population). I have averaged these two sets of values, and have obtained $9 \%$ as the average decrease in integrated morbidity of the ascorbic-acid subjects.

\section{WILSON, LOH, AND FOSTER}

Some studies involving several hundred students in four boarding schools in Dublin have been reported by Wilson and his collaborators. ${ }^{1213}{ }_{-}$As is mentioned by Dykes and Meier, their analysis of prophylactic benefit is much complicated by the subdivision of colds into three somewhat overlapping categories, catarrhal, toxic, and whole. The investigators state that the girls, in two schools were benefited, with statistical significance, by ascorbic acid, and that the boys, in the other two schools, were not. I have not been able to abstract from their papers any reliable value of the integratedmiorbidity for their subjects.

\section{COULEHAN, REISINGER, ROGERS, AND BRADLEY}

A double-blind study of 641 children in a Navajo boarding school was carried out over a 14-week period. ${ }^{15}$ The younger children received $1 \mathrm{~g}$ and the older children $2 \mathrm{~g}$ of ascorbic acid (or placebo) per day. The number of days of illness per subject was $28 \%$ less for the ascorbic-acid group of younger children than for the placebo group, and $34 \%$ less for the older children (weighted average $30 \%$ ). The statistical significance of this difference is uncertain.

\section{KARLOWSKI ET AL.}

The results of a double-blind ninemonths study with 190 employees of the National Institutes of Health have been reported recently by Karlowski, Chalmers, Frenkel, Kapikian, Lewis, and Lynch. ${ }^{2}$ The study was well designed and well executed except for the use of a poor placebo, easily distinguished from ascorbic acid by taste. Ascorbic acid, $1 \mathrm{~g}$ per day, was taken by 101 subjects (groups C and D, Table 1 ) of whom 57 (group D) also received an additional $3 \mathrm{~g}$ per day for the first five days of any illness, be-

\section{Table 1}

\begin{tabular}{|c|c|c|c|c|c|c|}
\hline \multirow[b]{2}{*}{ Group } & \multicolumn{5}{|c|}{ Summary of Results Reported by Karlowski et al. } & \multirow[b]{2}{*}{$\begin{array}{c}\text { Decrease } \\
\text { relative } \\
\text { to } \mathrm{A}\end{array}$} \\
\hline & $\begin{array}{l}\text { Number } \\
\text { of } \\
\text { subjects }\end{array}$ & Dose* & $\begin{array}{l}\text { Average } \\
\text { number } \\
\text { of colds }\end{array}$ & $\begin{array}{l}\text { Days of } \\
\text { ithness } \\
\text { per cold }\end{array}$ & $\begin{array}{l}\text { Days of } \\
\text { lliness } \\
\text { per person }\end{array}$ & \\
\hline$A$ & 46 & $\mathbf{P}+\mathbf{P}$ & $1.4 t$ & 7.1 & 10.01 & - \\
\hline B & 43 & $\mathbf{P}+\mathbf{V}$ & 1.30 & 6.5 & 8.45 & $16 \%$ \\
\hline $\mathrm{C}$ & 44 & $V+P$ & 1,18 & 6.7 & 7.91 & $21 \%$ \\
\hline $\mathrm{D}$ & 57 & $v+v$ & 1.33 & 5.9 & 7.85 & $22 \%$ \\
\hline
\end{tabular}

* The first $P$ means daily placebo, the first $V$ daily ascorbic acid $(1 \mathrm{~g})$, the second $P$ supplemental placebo, and the second $V$ supplemental ascorbic acid (3 $g$ per day for the first five days of any illness).

ginning, however, only after the subjects had returned to the pharmacy to have their symptoms and clinical observations recorded and to receive their supplemental capsules. A group (A) of 46 received only placebo capsules, and a group (B) of 43 received daily placebo capsules and ascorbic-acid supplementary capsules.

The reported average number of colds and average days of illness per cold are given in Table 1. The product of these (sixth column) is the average number of days of illness per person, which is a measure of the integrated morbidity. The subjects regularly taking $1 \mathrm{~g}$ of ascorbic acid per day (group C) had $21 \%$ less illness than the control group (A). Nearly the same amount of decreased illness was found for the group taking only supplemental ascorbic acid (B, 16\%) and the group taking both daily and supplemental ascorbic acid (D, 22\%). The weighted average, $20 \%$, of these three values is the observed decrease in integrated morbidity for all ascorbic-acid subjects relative to the placebo subjects. The statistical significance of this decrease cannot be calculated because the investigators do not give standard deviations of the averages or equivalent information.

Many of the subjects had tasted the contents of their capsules and correctly interpreted the taste. Much of the decreased illness was found in the subjects who learned in this way that they were receiving ascorbic acid. The investigators indicate that much of the apparent protective effect of ascorbic acid might be the result of a psychological effect, the power of suggestion. I doubt, as do some others, that such psychological effects can operate significantly in a large population over periods of several months, and I accept the results of the National Institutes of Health study with about as much confidence as the others.

Karlowski et al. conclude "that ascorbic acid had at best only a minor influence on the duration and severity of colds, and that the effects demonstrated might be explained equally well by a break in the double blind." They also say that "the effects of ascorbic acid on the number of colds seem to be nil," and this statement has been quoted in the AMA press release ${ }^{3}$ without the additional information about the number of colds given by Karlowski et al. In fact (Table 1), the group receiving prophylactic ascorbic acid had $16 \%$ fewer colds than the control group, and the three ascorbic-acid groups together had $10 \%$ fewer. It is not correct to say that the effects seem to be nil.

\section{References}

1. Dykes MHM, Meier P: JAMA 10 March

2. Karlowski TR $_{\mathrm{f}}$ Chalmers TC, Frenkel LK, Kapikian AZ, Lewis TL, Lynch JM: JAMA WMarch 1975 .

3. Vitamin $C$ will not prevent colds, say reports in AMA Journal. AMA press release, 10 March 1975.

4. Pauling L: Proc Nail Acad Sci USA 68:26782681. 1971.

5. Cowan DW, Diehl HS, Baker AB: JAMA 120:1268-1271. 1942

6. Franz WL, Sands GW, Heyl HL: JAMA 162' 1224-1226, 1956.

7. General Practitioner Research Group: Practi tioner 200:442-445. 1968

8. Ritzel G: Helv med Acta 28:63-68. 1961.

9. Anderson TW, Reid DBW, Beaton GH: Can Med Assoc J 107:503-508, 1972

10. Anderson TW, Reid DBW, Beaion GH: Can Med Assoc J 108:133. 1973.

11. Anderson TW, Swurjiri G, Beaton GH: Can Med Assoc J 111:31-36. 1974

12. Wilson CWM, Lob HS: Lancet 1.-638-641,

13. Wilson CWM, Lofc HS, Foster FG: Eur J Clin Pharmacol 6:26-32. 1973.

14. Wilson CWM, Lob HS, Foster FG: Eur J Clm Pharmacol 6:196-202. 1973,

IS.Coulehan JH, Reisinter KS, Roger* KD, Bradley DW: N Engl J Med 290\&-10, 1974. 